\title{
A Função de Desenvolvimento de Recursos Humanos do INAMPS/MPAS
}

\author{
* Médico Sanitarista, Diretor \\ do Departamento de Recursos \\ Humanos e Modernização Admi- \\ nistrativa da Direção Geral do \\ INAMPS
}

José Paranaguá de Santana *

\section{INTRODUÇÃO}

O conceito de desenvolvimento de recursos humanos (DRH) tem uma abrangência que extrapola o tratamento dado ao termo neste documento, pois considera, alem dos aspectos ligados à questão da capacitação ou preparação técnica e científica, aqueles referentes à dinâmica da força de trabalho, à sua inserção institucional e administração.

Não há, portanto, intenção de reduzir a dimensão conceitual do tema, mas, tão-somente, a deliberação de tratar os aspectos particulares da política, da estratégia e dos meios de que dispõe o INAMPS para enfrentar os desafios da preparação de recursos humanos adequados ao cumprimento de seus objetivos institucionais.

Por outro lado, ainda que explorando apenas tal aspecto do assunto, não seria correto fazê-lo em referência ao contexto no qual se inscreve a participação que o INAMPS vem tendo no processo de preparação de pessoal de saúde no País.

O papel tradicional do INAMPS nesta área desdobra-se em três componentes fundamentais:

a) formação de pessoal de nível superior, que corresponde a duas vertentes de atuação: preparação de especialistas em medicina, através dos programas de residência médica, que representam cerca de $25 \%$ da oferta anual de vagas no País; apoio ao sistema escolar de graduação das profissões de saúde, através dos programas de estágios curriculares e de internato, com oferta aproximada de 2.700 vagas anuais para graduandos;

b) formação de pessoal de nível médio, que corresponde também a duas linhas de atuação: preparação de auxiliares de enfermagem, através de seis escolas sediadas nas superintendências Regionais do Maranhão, Pernambuco, Bahia, Goiás, Rio de Janeiro e São Paulo; apoio à formação profissionalizante pretendida pelas escolas de $1^{\circ}$ e $2^{\circ}$ graus, através de estágios para cerca de 2.600 estudantes, anualmente;

c) treinamento e aperfeiçoamento do pessoal próprio: linha de ação tradicionalmente desenvolvida pelo sistema de pessoal, através da realização de treinamento segundo necessidades especificamente identificadas e da promoção de cursos ou estágios, tanto nos serviços próprios do Instituto, como através da liberação dos servidores para tais atividades oferecidas por outras instituições, no país ou no exterior.

A natureza, a diversidade e a dimensão das questões de preparação de recursos humanos adquirem caráter de verdadeiro desafio, quando se considera a composição e o volume de força de trabalho própria do INAMPS. Tal desafio, apre- 
senta proporções ainda mais amplas e complexas ao considerar-se a importância e o compromisso que o INAMPS vem assumindo no processo da Reforma Sanitária Brasileira.

É diante destes parâmetros que deve ser compreendido, no âmbito do INAMPS, o termo DRH, ainda que na abordagem restrita dos aspectos de capacitação de recursos humanos.

\section{SITUAÇĀO ATUAL E LINHAS DE ATUAÇĀO}

A decisão polf́tica de valorização da área de DRH no INAMPS se expressou em duas medidas, a primeira tomada logo no início da atual adminstração e a segunda, em fase final de implementação:

a) reformulação organizacional do sistema de DRH:

- criação do Departamento de Desenvolvimento de Recursos Humanos e Modernização Administrativa na Direção Geral e das Coordenadorias, nas Superintendências Regionais;

- definição de estrutura racional e funcionalmente ágil para as unidades operacionais do sistema de DRH;

- criação dos Centros Formadores de Pessoal de Nível Médio, a serem implantados a partir de Escolas de Auxiliares de Enfermagem.

b) descentralização administrativa e disponibilidade orçamentária para dinamização das atividades de capacitação.

As linhas de atuação do sistema podem ser agrupadas em duas vertentes: treinamento e aperfeiçoamento dos servidores e preparação de pessoal de saúde. Há outros recortes que permitiriam agrupar as ações segundo programas, identificando-o conforme peculiaridades próprias ou de suas clientelas: residência médica, estágio curricular e internato, aperfeiçoamento dentro e fora do próprio INAMPS, treinamento e reciclagem, educação continuada, capacitação de pessoal estratégico etc. $\mathrm{Na}$ abordagem feita a seguir, optou-se pela primeira alternativa classificatória.

\section{1 - TREINAMENTO E APERFEIÇOAMENTO}

O emperramento do processo administrativo, marcado pelo centralismo decisório decorrente das normas vigentes para o sistema de pessoal civil da União, bem como a escassez de recursos orçamentários, condicionaram, ao longo dos anos, atrofia e inércia do sistema de DRH do INAMPS.

Tal situação tem suas origens nas mesmas razões que levaram ao desprestígio dos serviços públicos junto à população. Se os hospitais e postos de assistência médica do INAMPS tiveram a sua estrutura e funcionamento relegados a segundo plano, e natural reconhecer-se a precariedade de organização e eficiência dos mecanismos e instrumentos de capacitação de sua força de trabalho. 
A reversão dessa situação passa por uma série de medidas e iniciativas que estāo sendo levadas a efeito, cuja maturação implica certa latência para o surgimento dos efeitos desejados:

a) Criação de condições para utilização de toda a capacidade operacional própria do sistema de DRH:

- sistematização da programação e orçamentação de atividades a serem realizadas;

- aquisição/produção de materiais e equipamentos de auxílio didático;

- definição de incentivos ao desempenho das funções de preceptoria, supervisão e coordenação de atividades ou programas de DRH;

- melhoria das condições e incentivos à pesquisa bibliográfica e à produção científica: reaparelhamento e organização das bibliotecas e criação da Revista do INAMPS.

b) Definição da política de aperfeiçoamento de pessoal, no país e no exterior: áreas prioritárias, instituições de referência, critérios de seleção e mecanismos para fomento da participação dos servidores em cursos ou estágios de interesse institucional.

c) Estabelecimento de programas de cooperação técnica em DRH, através de convênios com instituiçōes de ensino e pesquisa, de modo a criar oportunidades de realização de cursos e/ou estágio em áreas criticas e de interesse do INAMPS.

d) Fomento à participação de servidores em tais atividades, através da oferta de bolsas de estudo e pagamento de transporte.

O conjunto de medidas citadas, de fácil referência e compreensão, apresenta aspectos de grande complexidade, dada a magnitude e abrangência que implicam pensar e fazer DRH numa instituição com o porte e os compromissos, em termos da configuração atual do sistema nacional de saúde, que tem $o$ INAMPS. Os comentários a seguir alinhados traduzem o significado desta observação.

A mobilização da capacidade operacional do sistema de DRH do Instituto abrange cerca de 120 unidades tecnico-administrativas, situadas na Direção Geral e nas Superintendências Regionais. A superação das práticas institucionais, dependentes de decisöes centralizadas requer a qualificação das instâncias regionais e locais, num processo dinâmico em que o movimento de descentralização deve ser sinergico e não subseqüente ao desenvolvimento de tal qualificação. No entanto, a velocidade desse processo apresenta limitaçōes decorrentes de dois fatores fundamentais: as carências materiais e organizacionais que marcam a situação atual da rede assistencial e da malha administrativa do INAMPS, que não podem ser equacionadas no âmbito exclusivo do setor de $\mathrm{DRH}$; a indisposição funcional do pessoal para envolvimento com açōes de DRH, dada a tradicional inércia nesta área, aliada à impropriedade ou inexistência de fatores de valorização, em termos de grati- 
ficação ou incentivos ligados ao plano de carreira ou à vida funcional dos servidores.

É imperioso reconhecer, portanto, que a agilização e o incremento de modo expressivo das ações de DRH no INAMPS, passam pela redefinição da própria política de administração do pessoal da instituição.

A definição da política de aperfeiçoamento para o pessoal próprio é um processo que deve pautar-se em duas questōes anteriores, relativas ao perfil dos serviços que deve prestar o INAMPS e à forma de incorporação tecnológica por parte destes serviços. Em outras palavras, é a definição daquilo que deve ser feito e da organização do processo de trabalho que permite inferir a qualificação desejável para o trabalhador. Estas duas questões têm sido enfrentadas de modo aleatório, ao saber de determinações conjunturais adotadas em cada gestão administrativa. Por conseqüência, as diretrizes para as atividades de aperfeiçoamento carecem de profundidade e pertinência que assegurem o desenvolvimento de processos que, pela sua própria natureza, são de lenta maturação.

A perspectiva atual, sobre o aspecto acima, apresenta-se promissora na medida em que as duas questões levantadas vêm sendo objeto de preocupaçōes, estudos e decisōes: a reorganização do setor responsável pela administração das unidades assistenciais próprias e a criação da Coordenadoria de Ciência e Tecnologia foram medidas que permitirão o equacionamento e a implementação de diretrizes para os processos de aperfeiçoamento técnico e científico do quadro de pessoal do instituto, de forma condizente com as necessidades de operação da rede de serviço e, também, de modo coerente com os processos de incorporação tecnológica que se verificam nessa rede.

O estabelecimento de programas de cooperação técnica para DRH é um processo que apenas começa através da celebração de convênios com instituições de ensino e pesquisa. É, mais que isso, um esforço permanente que deve ser realizado conjunturalmente, visando a implementação de projetos e programas de capacitação de pessoal. Tal esforço esbarra em limitações próprias de sua fase inicial: a inexperiência na realização de trabalhos interinstitucionais; a dificuldade no estabelecimento de prioridades e estratégias de atuação conjunta; a pequena reserva técnico-acadêmica das instituições de ensino, mobilizável a curto prazo para o desenvolvimento de cursos e outras atividades necessárias ao processo de DRH das instituições de serviço.

O estímulo ou promoção da participação dos servidores em atividades de aperfeiçoamento engloba uma série de aspectos, alem daqueles ligados diretamente à participação em cursos ou estágios: auxílios de manutenção e transporte. É necessário criar condições que favoreçam a utilização ou aplicação dos conhecimentos e habilidades adquiridos, sem o que perde-se o objetivo final do próprio aperfeiçoamento. Tais condições, na maioria dos casos, estão ligadas ou são as próprias condiçōes 
materiais e organizacionais dos setores ou serviços aos quais estão vinculados os servidores envolvidos nas atividades de aperfeiçoamento.

\section{2 - PREPARAÇÃO DE PESSOAL}

No tocante ao papel do INAMPS como contribuinte do sistema de formação de pessoal de saúde, sua participação diz respeito a três linhas programáticas já tradicionais na história das entidades da previdência social: preparação de especialistas, com ênfase quase absoluta para a residência médica; treinamento de estudantes de nível médio e superior, através dos estágios curriculares; e formação de auxiliares de enfermagem.

Reconhecendo que o eixo das medidas necessárias à revisão da formação de pessoal em saúde, no país, passa pelo sistema educacional, a postura do INAMPS tem sido a busca de entendimento com os órgãos de educação, no sentido da elaboração de decisões conjuntas e atuação compartilhada para objetivos de comum interesse.

Nesta área, há amplo consenso de que os processos atuais de formação de pessoal, em todos os níveis educacionais, está em dissensão com as diretrizes da política setorial de saúde, quando esta se dirige para a universalização e a eqüidade do direito e acesso aos bens e serviços de saúde.

Reconhecendo a necessidade de melhor alinhamento entre as políticas de saúde e de formação de pessoal, a estratégia adotada considera as seguintes medidas:

a) Adesão efetiva do INAMPS ao projeto larga Escala (Acordo MEC/MS/MPAS/MCT/OPAS):

- inclusão do INAMPS nos projetos já implementados nos estados do Piauí, Rio Grande do Norte, Alagoas e Minas Gerais;

- implementação do projeto, em atuação com MS, MEC, e OPAS, em mais 10 estados; aqui inclui-se a trasformação das 6 Escolas de Auxiliares de Enfermagem do INAMPS em Centros de Formação Multiprofissional.

b) Sistematização e intensificação do programa de estágios curriculares de nível médio, através de entendimentos político-institucionais com o MEC, as Secretarias de Educação dos estados e convênios com as escolas.

c) Reformulação operacional dos estágios curriculares de graduação das carreiras de saúde, inclusive o internato, visando contribuir para formação de profissinais mais adequados ao atendimento das necessidades de saúde da maioria da população; a proposta mais abrangente, referente a esta questão específica, é a definição de um programa conjunto, entre os serviços e as escolas, abrangendo toda a rede pública de saúde, de modo a oferecer oportunida- 
de de cumprimento do estágio previsto pela regulamentação oficial dos respectivos currículos, para todos os estudantes das profissões de saúde.

Por último, resta referir a questão da preparação de especialistas em medicina. Dada a magnitude e a importância que a residência médica tem no contexto da pós-graduação na área da saúde (bem como no âmbito próprio do INAMPS), faz-se indispensável a realização de amplo debate, através da Comissão Nacional de Residência Médica, sobre o papel e o compromisso que deve ter este mecanismo de formação de especialistas no Brasil, em face das transformaçōes propostas para a organização e o funcionamento dos serviços de saúde no País.

\section{COMENTÁRIOS FINAIS}

As considerações apresentadas neste documento sobre a função de DRH do INAMPS procuraram situá-la no contexto e na dimensão que tem o próprio Instituto na configuração atual do sistema nacional de saúde. No entanto, é necessário também analisá-la na perspectiva do reordenamento desse sistema, proposto hoje pelo próprio Governo da Nova República.

Parte muito expressiva da força de trabalho em saúde no Brasil está vinculada, direta ou indiretamente, ao sistema previdenciário, o que decorre do fato dos serviços em que trabalham serem mantidos ou financiados, em maior ou menor extensão, com recursos da previdência social. Esta constatação deve ser levada em conta, como aspecto de capital importância, na definição de uma política nacional de recursos humanos em saúde.

No que se refere às questões abordads neste trabalho, ou seja, o recorte das questões de capacitação de recursos humanos, dada a importância da ação financeira e normativa do sistema previdenciário.

É, assim, nessa perspectiva que se define a função de DRH no INAMPS: interligada e interdependente da função de DRH do setor saúde como um todo.

\section{REFERÊNCIA BIBLIOGRÁFICA}

- SANTANA, José Paranaguá de. A função de desenvolvimento de recursos humanos no INAMPS/MPAS. p. 7 (mimeo).

"Contrıbuição para o setor saúde no Brasil. A situação da Categoria Médica". 